Recepción: 17 / 07 / 2018

Aceptación: 23 / 09 / 2018

Publicación: 05 / 10 / 2018

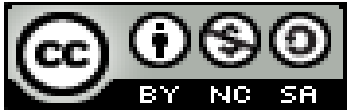

Ciencias sociales y políticas

Artículo original

\title{
Factores que inducen al abandono del tratamiento en pacientes con tuberculosis del centro de salud Cisne 2, periodo 2017
}

\section{Factors that lead to the abandonment of treatment in patients with tuberculosis from the Cisne 2 health center, 2017 period}

\section{Fatores que levam ao abandono do tratamento em pacientes com tuberculose do centro de saúde Cisne 2, período 2017}

\author{
Carmen A. Sánchez-Hernández ${ }^{\text {I }}$ \\ carmen.sanchezh@ug.edu.ec \\ Gloria J. Muñiz-Granoble II \\ janeth_muñizgranoble@ hotmail.com \\ Cinthya L. Rodríguez-Orozco III \\ cinthya.rooz@gmail.com
}

Correspondencia: carmen.sanchezh@ug.edu.ec

\footnotetext{
I Especialista en Salud Comunitaria, Especialista en Gestión Administración y Liderazgo en Servicios de Salud, Licenciada en Enfermería, Docente de la Universidad de Guayaquil, Guayaquil, Ecuador.

${ }^{\text {II } M a g i ́ s t e r ~ e n ~ E d u c a c i o ́ n ~ S u p e r i o r, ~ E s p e c i a l i s t a ~ e n ~ E n f e r m e r i ́ a ~ O n c o l o ́ g i c a, ~ L i c e n c i a d a ~ e n ~ E n f e r m e r i ́ a, ~}$ Docente de la Universidad de Guayaquil, Guayaquil, Ecuador.

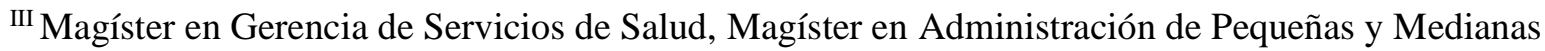
Empresas, Licenciada en Enfermería, Licenciada en Mercadotecnia, Docente, Universidad de Guayaquil, Guayaquil, Ecuador.
} 


\title{
Resumen
}

El abandono del tratamiento como agravante de la Estrategia de Prevención y Control de Tuberculosis en los Establecimientos de Salud, constituye una problemática a la Salud Publica, por el riesgo de incrementar la resistencia bacteriana en los pacientes. Esto motivó el objetivo de esta investigación, como determinar los factores que inducen al abandono del tratamiento de tuberculosis en el Centro de Salud Cisne 2 en el periodo 2017. Método: Estudio descriptivo de corte transversal con enfoque cuantitativo, aplicando una encuesta con escala tipo Likert modificada a la población del Centro de Salud Cisne 2 que abandonaron el tratamiento de tuberculosis pulmonar en el año 2017. Resultados: se reportaron 25 casos en el periodo 2017, el cual fue valorado 15 casos que abandonaron el tratamiento. Conclusiones: El factor social es uno de los principales que no permiten continuar con el tratamiento, por lo que se evidencia la desmotivación que lleva el paciente al asistir cada día a la institución de salud, siendo estos que los medios de transportes son un equivalente del $75 \%$ son triciclos, caminatas, factor económico, el $40 \%$ de los pacientes no cuentan con los recursos para asistir a la institución.

Palabras clave: Tuberculosis; abandono; tratamiento; salud; enfermedades.

\begin{abstract}
The abandonment of treatment as an aggravating factor of the Prevention and Control of Tuberculosis in Health Establishments, constitutes a problem for Public Health, due to the risk of increasing bacterial resistance in patients. This motivated the objective of this research, such as determining the factors that lead to the abandonment of tuberculosis treatment in the Swan Health Center 2 in the 2017 period. Method: Descriptive cross-sectional study with a quantitative approach, applying a Likert scale survey modified to the population of the Center of Health Cisne 2 that left the treatment of pulmonary tuberculosis in the year 2017. Results: 25 cases were reported in the period 2017, which was valued 15 cases that left the treatment. Conclusions: The social factor is one of the main factors that does not allow to continue with the treatment, which is why there is evidence of the lack of motivation that the patient has when attending the health institution every day, being that the means of transport are an equivalent of the $75 \%$ are tricycles, walks, economic factor, $40 \%$ of patients do not have the resources to attend the institution.
\end{abstract}

Keywords: Tuberculosis; abandonment; treatment; health; diseases. 


\section{Resumo}

Descontinuação do tratamento como uma estratégia agravante para Prevenção e Controle da Tuberculose em unidades de saúde constitui um problema de saúde pública devido ao risco de aumento da resistência bacteriana em pacientes. Isso motivou o objetivo desta pesquisa, tais como determinar os fatores que levam ao abandono do tratamento da TB no Centro de Saúde Cisne 2 no Método período de 2017. Um estudo descritivo transversal, com abordagem quantitativa, aplicando uma pesquisa escala de Likert modificada a população Swan Centro de Saúde 2 abandonaram o tratamento da tuberculose pulmonar em 2017. Resultados: 25 casos foram notificados no período de 2017, que foi avaliado 15 pacientes que descontinuaram o tratamento. Conclusões: $\mathrm{O}$ fator social é um dos principais que não permitem para continuar o tratamento, então a motivação que leva o paciente a participar de todos os dias na instituição de saúde é evidente, sendo estes os meios de transporte são equivalentes $75 \%$ são triciclos, caminhadas, fator econômico, $40 \%$ dos pacientes não possuem recursos para atender a instituição.

Palavras chave: Tuberculose; abandono; tratamento; saúde; doenças.

\section{Introducción}

Según la OMS (2014), considera que la tuberculosis perturba potencialmente la salud en general: física, mental, sin embargo, ejecuta un gran aporte que es brindar la solución a esta demanda como es el tratamiento. En este momento la Tuberculosis conmueve a la mayor población vulnerable como aquella que se encuentren con un sistema inmune bajo, caracterizando el entorno de la persona que es portadora, principal fuente para esparcir esta patología seguidos por diversas campañas estatales gratuitas, sin embargo, la prevalencia se mantiene. La problemática de esta patología se ve reflejada en la afluencia de pacientes que asisten a las instituciones de salud para una atención, siendo así los casos ambulatorios, o que ya reciben la medicación diferidos en los centros de salud, muchas veces los usuarios solo retiran la medicación, otros no lo hacen simplemente la descontinúan y abandonan el tratamiento lo que ocasiona que la patología continúe afectando el estatus de vida y salud del paciente.

Según León (2014), en la investigación titulada: “Tuberculosis Pulmonar, Diagnóstico, Programa y Control", en Ecuador la meta de abandono de tratamiento contra la tuberculosis es menor al 
6\%, aunque en el 2010 se situaba en el $28 \%$ los números de casos de abandono en la Tuberculosis, este año se obtuvo el 11,41\% de casos fallecidos con esta enfermedad, lo cual aumenta el riesgo de muerte al desatender el tratamiento por diferentes factores que pueden provocar el abandono del tratamiento del paciente.

Uno de los preocupantes motivos para el tratamiento, es el ausentismo de los pacientes en la medicación, muchos casos influyen en el entorno del paciente que desiste a su tratamiento complicando más su estado de supervivencia y a la vez generando la propagación de la enfermedad, durante el año 2015 hasta la fecha el Ministerio de Salud Pública del país ejecuta en diversas campañas de salud de prevención con orientación educacional "Respira Ecuador Libre de Tuberculosis", el cual tiene como característica principal lograr que en la población se trate de controlar la patología. (OMS, Porcentajes mundiales de países con mayor índice de tuberculosis, tratamiento, ausentismo de la medicación, 2015)

El problema se presenta en el Centro de Salud Cisne II, cuando enfermería asegura que los pacientes con $\mathrm{TB}$ registrados para su tratamiento, abandonan la continuidad del mismo por diversos factores. Durante este estudio de investigación logramos observar que los pacientes al ser diagnosticados con esta patología reaccionaban de manera negativa, relacionando la enfermedad con la muerte, desistiendo del tratamiento ya que piensan que es en vano llevar una terapia contra la $\mathrm{Tb}$.

Una de las causas para el abandono del tratamiento es no tener un domicilio fijo y cercano a la institución de salud donde recibe el tratamiento, el cual dificulta trasladarse. Algunos pacientes no cuentan con la capacidad económica favorable, no poseen trabajo estable e incluso algunos son vagabundos que no cuentan con vivienda, por lo que podrían ocasionarle depresión constante y lo menos que piensan es asistir a la toma de los antifímicos, más bien abandonan el tratamiento y ven como la oportunidad de que la enfermedad empeore conllevándolos a la muerte y así no sufrir más.

Por otro lado, podría haber pacientes que no tiene una familia o si la tienen, no los respaldan con el apoyo emocional necesario para continuar con el tratamiento de esta enfermedad, el cual es un agente causal para el abandono, hay casos de pacientes que dependen económicamente de su familia y cuando no tienen dinero para el traslado dejan de asistir al centro de salud. 
En otros casos uno de los factores relevantes para el abandono del tratamiento son los efectos secundarios tales como cefalea, nauseas, fiebre, diarreas, malestar corporal, etc., que en ciertas ocasiones aparecen después de la administración de medicamentos. También uno de los factores importantes para el abandono es la falta de conocimiento sobre la enfermedad, puesto que, si el paciente obtuviese la información de la importancia del tratamiento, no se dejará llevar por el resto de los factores antes mencionados y cumpliría con la asistencia al tratamiento. Estas situaciones desencadenan algún tipo de deterioro en la salud del paciente, interviniendo en el desempeño de la vida diaria de los mismos. El profesional de enfermería interviene de forma positiva y siempre precautelando el bienestar de los sujetos en el Centro de Salud Cisne II, el concientizar sobre la patología y sus consecuencias, si llegan a incurrir en el abandono del tratamiento.

En la actualidad debido al entorno en que se encuentran estas personas diagnosticadas con tuberculosis, sin dejar de mencionar también causas psicológicas de negatividad a la enfermedad, en la actualidad es inevitable la interacción entre múltiples factores de riesgo para el abandono del tratamiento, e incluye aquellos que provienen del ambiente físico, trastornos de las funciones biológicas, la organización del trabajo y diversos componentes psicosociales. (Ramírez \& Ramírez, 2015)

El propósito de este estudio de investigación es determinar los factores social, personal, económico y educativo que intervienen para que el paciente abandone su tratamiento. En el mencionado centro de salud, pudimos constatar el incremento en ausentismos de estas personas, lo que nos hizo evaluar y analizar el por qué el negativismo hacia la sanación de la enfermedad, de dónde surge la siguiente interrogante:

¿Cuáles son los factores que inducen al abandono del tratamiento de tuberculosis en el "Centro de Salud Cisne No. II"?

\section{Materiales y métodos}

\section{Tipos de investigación}

El presente estudio realizado, está enfocado en una investigación cuantitativa, de tipo descriptivo, mediante los cuales se sustentarán y detallarán los posibles factores que más inducen al 
Abandono del Tratamiento de la Tuberculosis en los pacientes atendidos en el Centro de Salud Cisne 2, de la ciudad de Guayaquil, durante el periodo 2017.

Este tipo de investigación implica considerablemente más esfuerzo que cualquiera otra investigación, ya que está enfocada en el tiempo, lugar y persona que ocurren los hechos de estudios. Además de la recolección, tabulación y análisis de datos necesarios, deben también enfocarse numerosos y a veces abrumadores asuntos operativos. Este proceso investigativo con metodología cuantitativa está elaborado bajo la modalidad de una investigación de campo o también conocida como directa, que se efectúa en la persona, lugar y tiempo en que ocurren los fenómenos de hecho. (Sampieri, 2014)

\section{Población y muestra}

Estará establecida una población de 25 pacientes del Programa de Estrategia y Control de la Tuberculosis en el periodo 2017, en las cuales aplicáremos el método de checklist a registros tales como libro de control, registro de toma de medicación, historias clínicas, de 15 casos que están incluidas en el abandono del tratamiento, en donde plasmaremos todas las vivencias, causas y motivos incidentes que conllevaron al abandono del tratamiento de tuberculosis. Con criterios de inclusión: casos nuevos con tuberculosis pulmonar y casos con tratamiento con tuberculosis pulmonar. Criterio de exclusión: pacientes con retratamiento que recibe esquema y pacientes con drogo resistencia.

\section{Recolección de datos}

Se utiliza para la recolección de la información son las entrevistas a los responsables de las Estrategias de Control de la Tuberculosis en los Establecimiento de Salud, la observación directa en los registros de los pacientes, para la aplicación del formulario de recolección de datos, análisis de datos de los libros de casos de pacientes y cohorte de tratamiento. El análisis, interpretación y presentación de datos se basará en un estudio comparativo entre el marco teórico referencial y la realidad encontrada, mediante el análisis de discusión de datos.

Formularios de recolección de datos elaborados por los investigadores para este fin, libro de registros de casos de tuberculosis, historias clínicas y registro de visitas domiciliarias, instituida en el establecimiento de salud, los mismos que permitieran cumplir con el fin de la investigación. 


\section{Análisis y discusión de datos}

Después de organizados los datos en tablas y gráficos estadísticos descriptivos, se procede a realizar el análisis y discusión de los resultados más relevantes del estudio.

\section{Género}

Tabla 1. Género

\begin{tabular}{lcl}
\hline Alternativas & Frecuencia & Porcentaje \\
\hline Masculino & 20 & $95 \%$ \\
Femenino & 5 & $5 \%$ \\
Total & $\mathbf{2 5}$ & $\mathbf{1 0 0 \%}$ \\
\hline
\end{tabular}

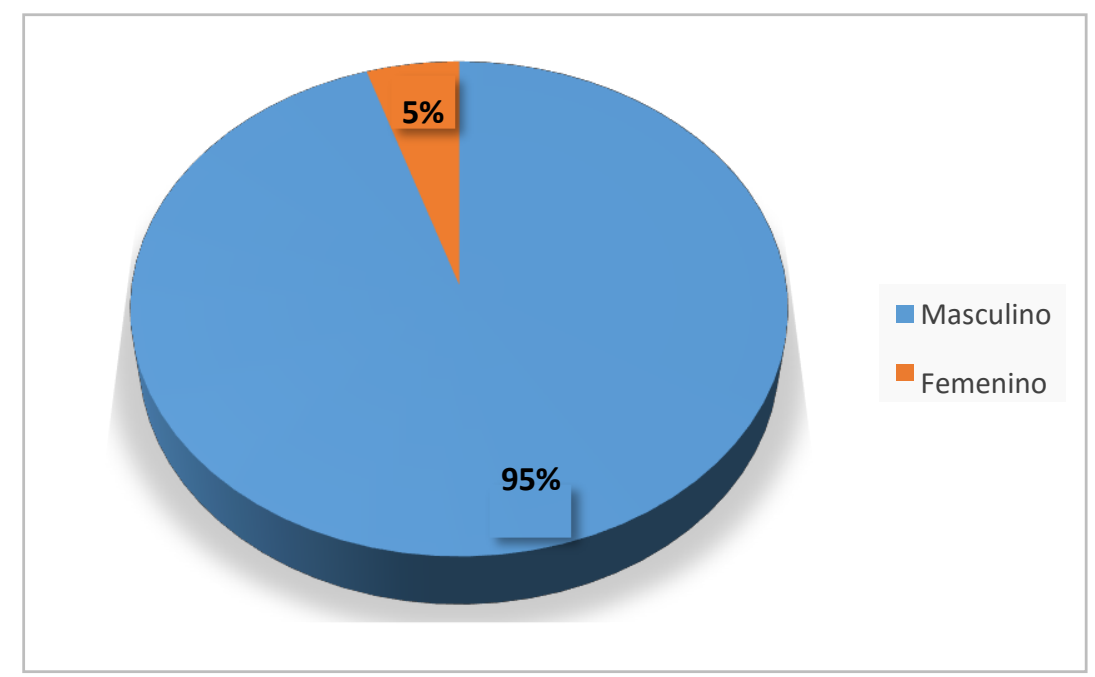

Gráfico 1. Género

Fuente: Programa Control de Tuberculosis, Centro de Salud Cisne 2

Análisis: De la encuesta realizada se obtuvieron los siguientes datos, que el 95\% de la población del estudio pertenecen al género masculino, mientras que el $5 \%$ son de género femenino, siendo este relevante que la más alta de los sujetos de la indagación son hombres, objetando que el porcentaje inferior pertenece a las mujeres.

Un estudio realizado por Miranda es que el $68.4 \%$ de los casos fueron del sexo masculino y el $31,6 \%$ otorgado al sexo femenino. (Miranda, 2015)

Mediante la presente investigación, se apunta que la mayoría de pacientes que abandona el tratamiento es la población del género masculino, que mantiene dentro de su organismo 
circulando la patología, pero no deja de pasar desapercibidos el índice inferior de mujeres, ya que si enfocamos en un nivel comparativo cuántos de estos hombres mantiene pareja y si realizamos un cerco epidemiológico los índices sustancialmente cambiarían.

\section{Procedencia}

Tabla 2. Procedencia

\begin{tabular}{lll}
\hline Alternativas & Frecuencia & Porcentaje \\
\hline Rural & 1 & $10 \%$ \\
Urbana & 24 & $90 \%$ \\
Total & $\mathbf{2 5}$ & $\mathbf{1 0 0 \%}$ \\
\hline
\end{tabular}

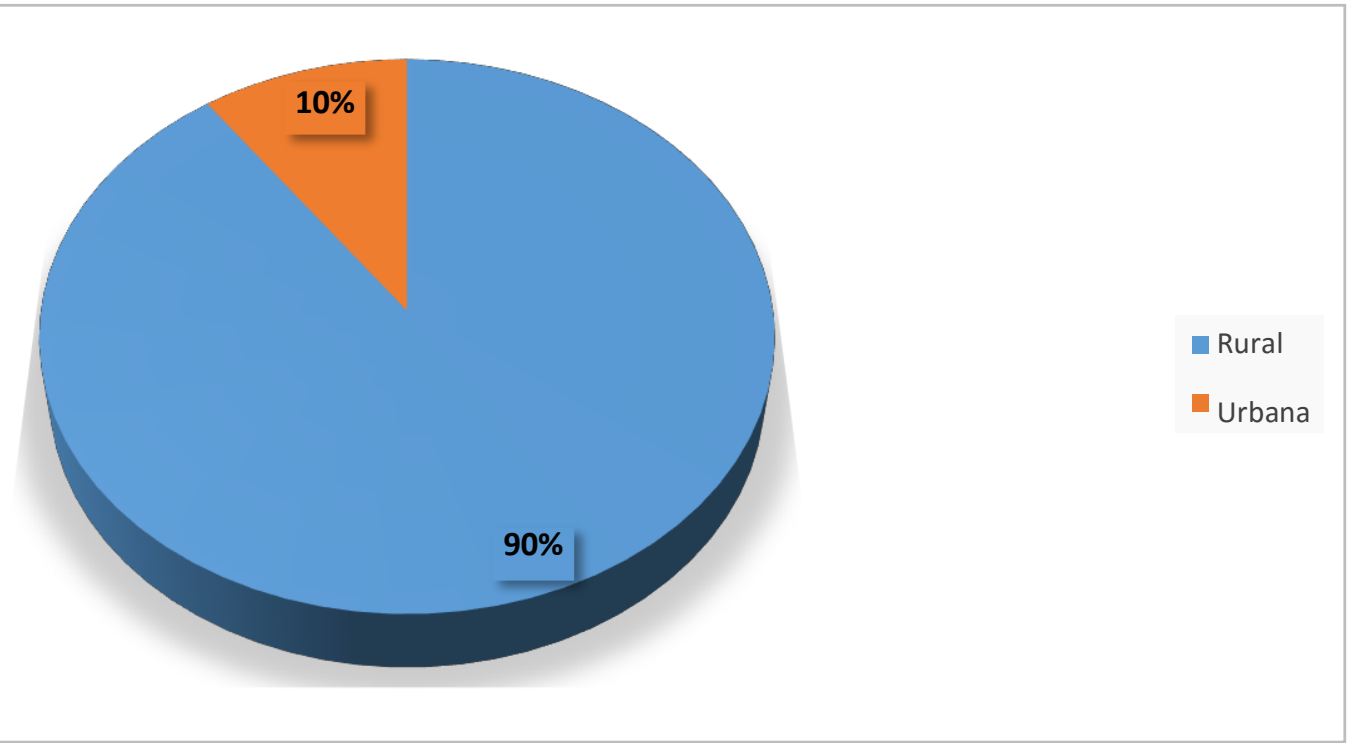

Gráfico 2. Procedencia

Fuente: Programa Control de Tuberculosis, Centro de Salud Cisne

Análisis: La encuesta recogió la siguiente información que el 90\% de la población pertenece al sector urbano mientras que un $10 \%$ al sector rural, siendo esto una población numerosa, altamente densa, y dedicada principalmente a actividades del sector secundario

Un estudio realizado en la ciudad de Medellín en una investigación titulada: "Factores asociados al éxito del tratamiento de los pacientes con tuberculosis 2014", muestra con 65 pacientes, evidenciado que el 50\% de los pacientes del área urbano no culminaban su tratamiento. (Ramírez \& Ramírez, 2015) 
Los resultados en el estudio y el análisis de la investigación obtenidos reflejan que la procedencia urbana es la más afectada, ya que su población es el foco principal de expandir la enfermedad con un $90 \%$ en su mayor índice.

\section{Forma en que fue captado}

Tabla 3. Forma en que fue captado

\begin{tabular}{lcl}
\hline Alternativas & Frecuencia & Porcentaje \\
\hline Consulta Externa & 5 & $30 \%$ \\
Búsqueda de sintomáticos & 18 & $60 \%$ \\
respiratorios & & \\
Otros & 2 & $10 \%$ \\
$\quad$ Total & $\mathbf{2 5}$ & $\mathbf{1 0 0 \%}$ \\
\hline
\end{tabular}

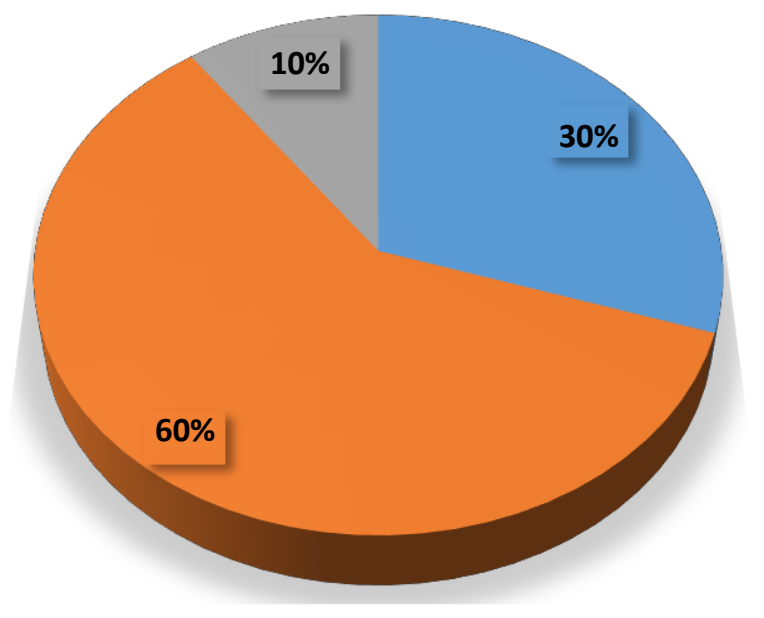

- Consulta Externa

-

Búsqueda de sintomáticos respiratorios

Otros

Gráfico 3. Forma en que fue captado

Fuente: Programa Control de Tuberculosis, Centro de Salud Cisne 2

Análisis: La encuesta recogió los siguientes datos en donde se analiza y se procesa la información, en donde se estudió a los sujetos la forma que acudieron y forma en que fueron captados, los pacientes captados en la búsqueda de sintomáticos respiratorios corresponde al $60 \%$, siendo estos datos que a continuación se detallan, con el $30 \%$ en consulta externa, finalizando en Otros con un $10 \%$.

La institución es la encargada de captar a los pacientes con tuberculosis que se encuentren al alrededor de ésta, ya que estos enfermos son las principales fuentes de infección y contagio, 
cuanto más rápidamente se identifiquen las fuentes de infección, se las trate y cure adecuadamente, se va disminuyendo así el nivel de propagación.

\section{Consumo de drogas y alcohol}

Tabla 4. Consumo de D/A

\begin{tabular}{lcl}
\hline Alternativas & Frecuencia & Porcentaje \\
\hline $\mathrm{Si}$ & 7 & $30 \%$ \\
No & 18 & $70 \%$ \\
Total & $\mathbf{5}$ & $\mathbf{1 0 0 \%}$ \\
\hline
\end{tabular}

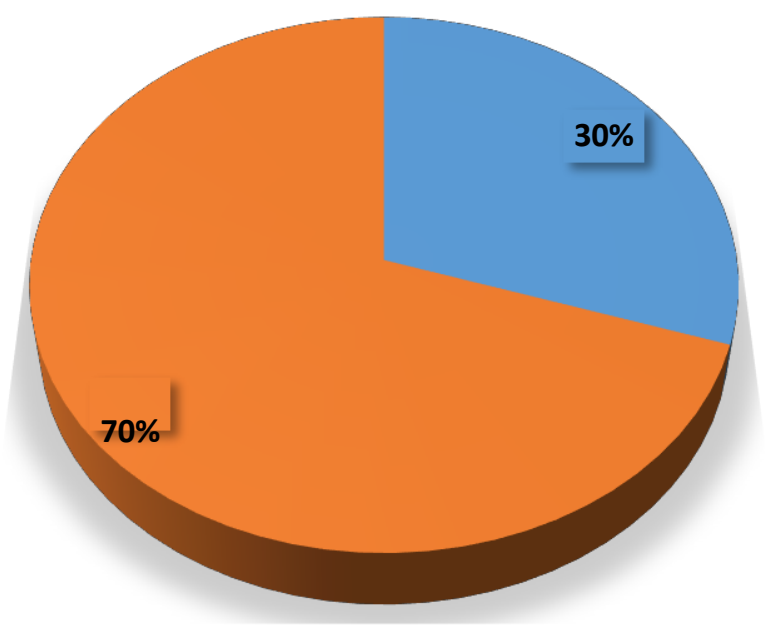

Gráfico 4. Consumo de D/A

Fuente: Programa Control de Tuberculosis, Centro de Salud Cisne 2

Análisis: Los datos refieren que el $70 \%$ de la población del estudio de investigación, difundió que de los sujetos de la población objetaron no mantener ningún tipo de consumo de drogas, mientras que otro $30 \%$ abordó que si son consumidores de estupefacientes.

Un estudio mostró que existía proporciones semejantes en el consumo frecuente de tabaco en ambos grupos estudiados, el consumo frecuente de alcohol mostró una relación significativa con una mayor probabilidad de abandonar el tratamiento, demostraron que el alcoholismo estuvo presente en $45.9 \%$ del grupo con abandono, a diferencia de $4.9 \%$ del grupo de no abandono (Cristhian, 2016) 
Como resultado de la investigación, un indicante favorable al no mantener dependencia a ningún estupefaciente, ayudar a mantener una constancia en el desarrollo diario al tratamiento, esto es evidenciado en el análisis de los datos de la encuesta con un porcentaje de $30 \%$ que si lo hace, cual éste generan problemas, es decir será el porcentaje que se ausentaran por la mismas dependencia que mantienen a los estupefacientes al abandonar el tratamiento de tuberculosis.

\section{Hubo apoyo familiar cuando presento la enfermedad}

Tabla 5. Apoyo familiar

\begin{tabular}{lll}
\hline Alternativas & Frecuencia & Porcentaje \\
\hline $\mathrm{Si}$ & 23 & $90 \%$ \\
No & 2 & $10 \%$ \\
Total & $\mathbf{2 5}$ & $\mathbf{1 0 0 \%}$ \\
\hline
\end{tabular}

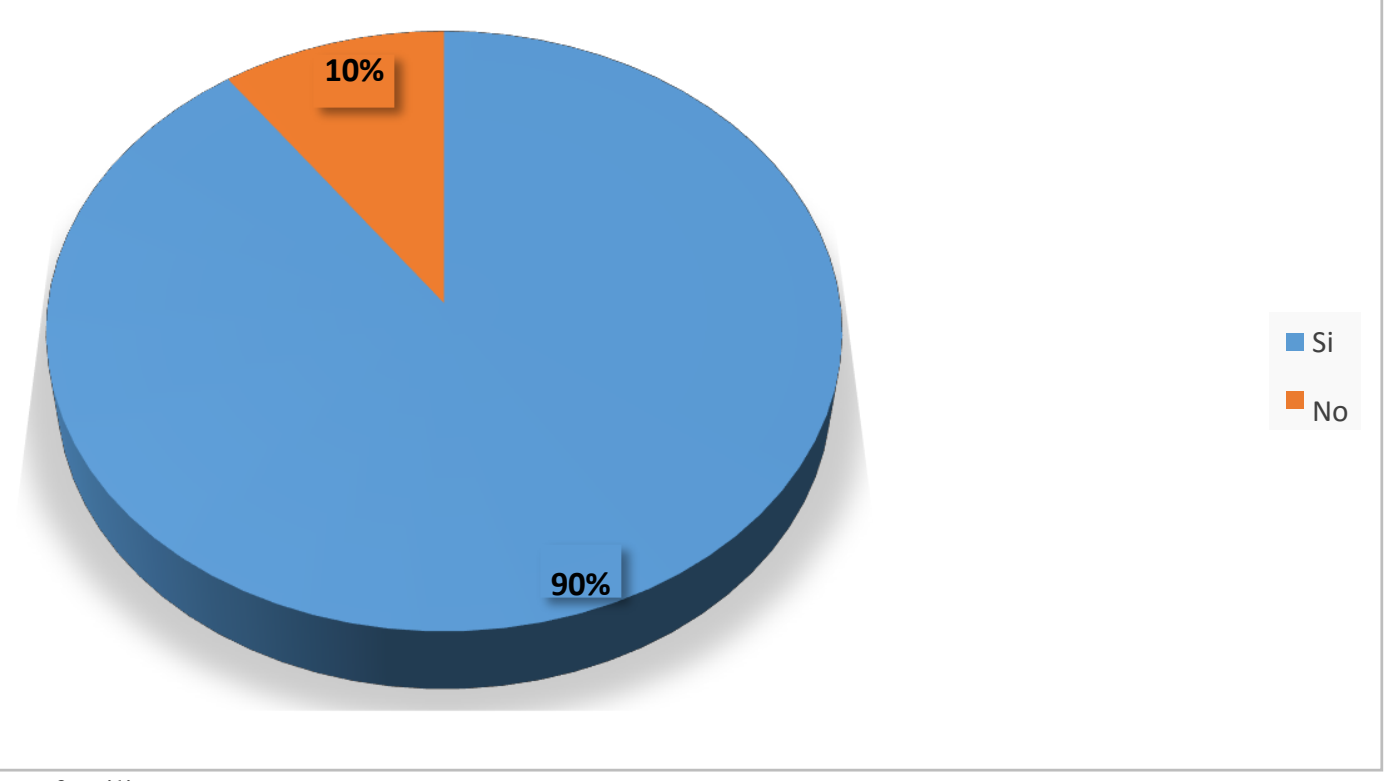

Gráfico 5. Apoyo familiar

Fuente: Programa Control de Tuberculosis, Centro de Salud Cisne 2

Análisis: La encuesta recogió la siguiente información que el 90\% de la población si mantuvo apoyo familiar cuando presento la enfermedad, mientras que un porcentaje del $10 \%$ contesto que no mantuvieron ningún tipo de apoyo por parte de sus familiares cercanos ni lejanos. 
Un estudio planteo que valorarse uno mismo es fundamental para continuar con el tratamiento de tuberculosis, en el caso de los sujetos de la investigación muchos se aíslan en el sentido que mantiene ocultos por el motivo de la enfermedad, otros se vuelven depresivos esto es lo que termina afectando para así abandonar el tratamiento. (Rodríguez, 2014)

Respecto al análisis de datos de la investigación se concluye que el apoyo emocional es muy sustancial para el individuo que mantiene esta afectación, éste ayudará notablemente a que mantenga un estado de ánimo positivista para lograr y mantenerse constante en el tratamiento y así evitarse que incida en un abandono temprano del mismo.

\section{Apoyo laboral cuando presento la enfermedad}

Tabla 6. Apoyo laboral

\begin{tabular}{lcl}
\hline Alternativas & Frecuencia & Porcentaje \\
\hline $\mathrm{Si}$ & 18 & $70 \%$ \\
$\mathrm{No}$ & 7 & $30 \%$ \\
Total & $\mathbf{2 5}$ & $\mathbf{1 0 0 \%}$ \\
\hline
\end{tabular}

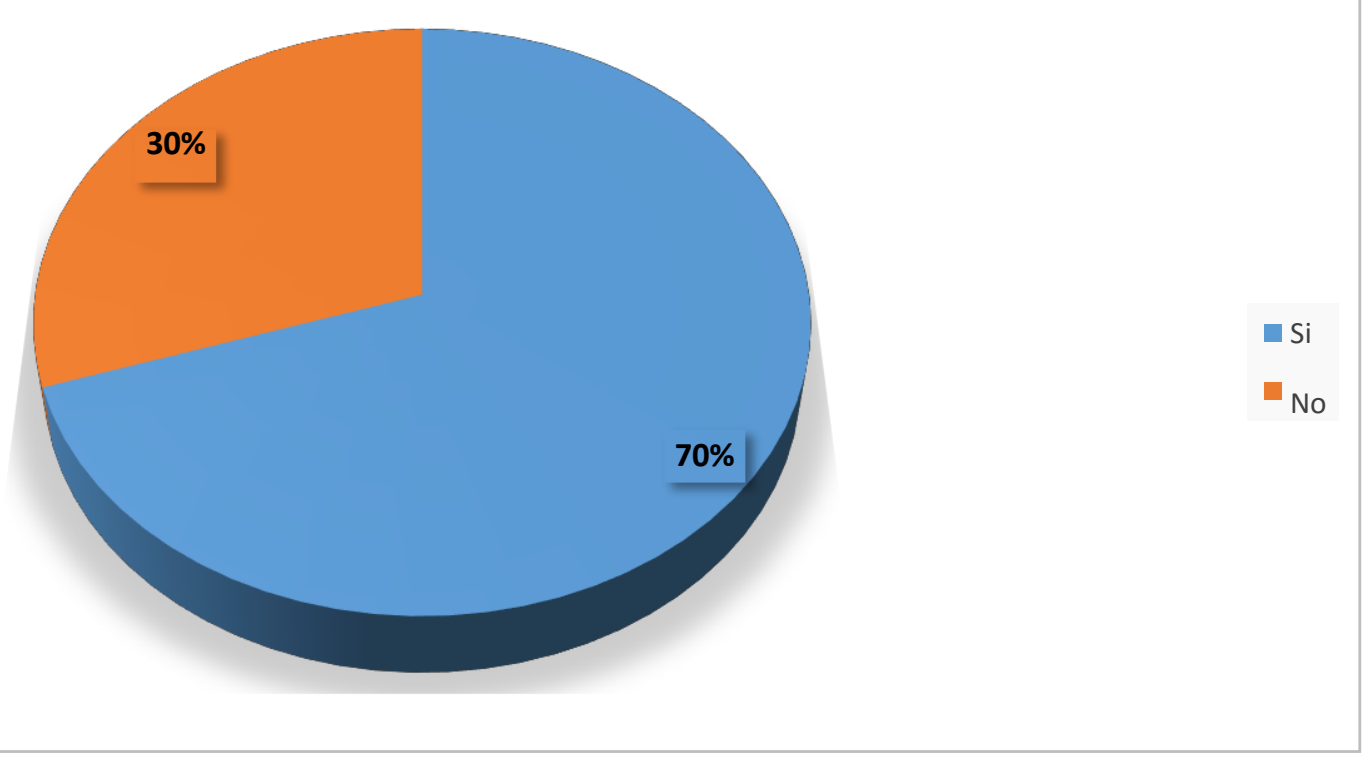

Gráfico 6. Apoyo laboral

Fuente: Programa Control de Tuberculosis, Centro de Salud Cisne 2 
Análisis: La encuesta recogió la siguiente información que el $70 \%$ de los sujetos de la investigación si mantuvieron apoyo laboral cuando se les presento la enfermedad, mientras que el 30\% manifestó que no mantuvo ningún tipo de apoyo.

La enfocaremos en el entorno del sujeto del estudio, entorno social, laboral, carente, inestable, vulnerable a cualquier funcionabilidad, validando el estatus de las necesidades a acorde a lo desarrollado en emperica, en donde la exaltación laboral se logra la determinación de afianzar, y fortalecer al individuo, así encaminarlo a una cura pertinente. (Álvarez, 2014)

En conclusión, el apoyo laboral es fundamental, evidenciado en el estudio de la investigación con un $70 \%$ de las personas con TB si fueron apoyados, siendo éste una de las necesidades principales como es el afecto y estimación de los demás que están alrededor, el cual ayudará a su no abandono con el tratamiento.

\section{Apoyo social cuando presento la enfermedad}

Tabla 7. Apoyo social

\begin{tabular}{lll}
\hline Alternativas & Frecuencia & Porcentaje \\
\hline $\mathrm{Si}$ & 5 & $20 \%$ \\
$\mathrm{No}$ & 20 & $80 \%$ \\
Total & $\mathbf{2 5}$ & $\mathbf{1 0 0 \%}$ \\
\hline
\end{tabular}

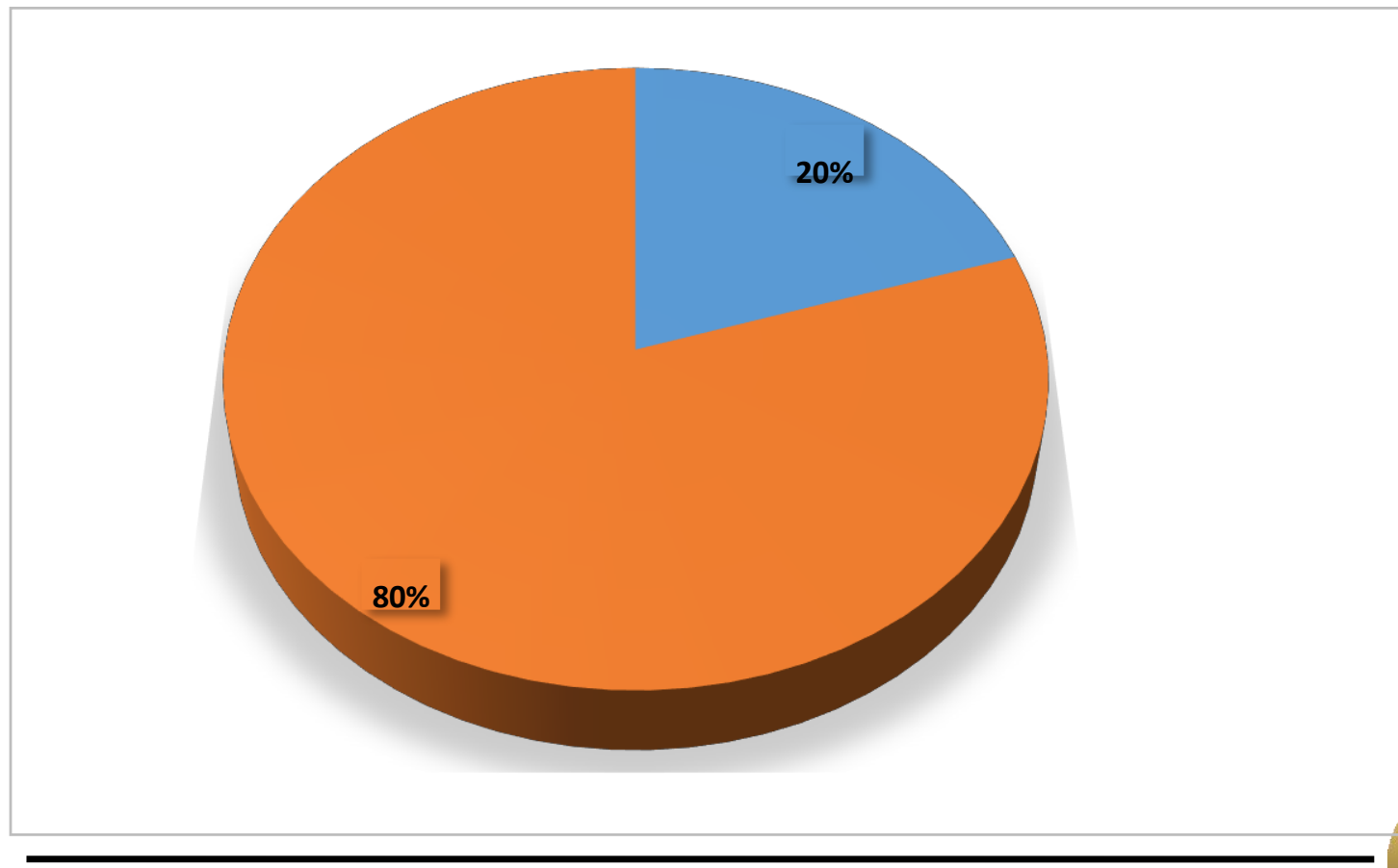


Gráfico 7. Apoyo social

Fuente: Programa Control de Tuberculosis, Centro de Salud Cisne 2

Análisis: Los datos de este estudio refieren que el $80 \%$ de los sujetos de la investigación mantuvieron apoyo social cuando presentó la enfermedad, mientras que el 20\% de la población del estudio refirió que no mantuvieron ningún apoyo social durante el tiempo que presentó la patología y durante su tratamiento.

Un estudio realizado por Coello (2015), indica que un 50\% de los usuarios consideraba que su familia y amigos siempre le daban apoyo emocional para afrontar el tratamiento de la enfermedad, pero un $30 \%$ considera que el apoyo social y familiar era rechazado.

Se demuestra entre el estudio y la investigación realizada que el apoyo social es principal para que el paciente con esta patología llegue a culminar su tratamiento, en el estudio se evidencia que el $80 \%$ de los pacientes si obtuvieron apoyo social durante su tratamiento.

\section{Apoyo del profesional de enfermería durante el tratamiento}

Tabla 8. Apoyo del profesional de enfermería

\begin{tabular}{lcl}
\hline Alternativas & Frecuencia & Porcentaje \\
\hline $\mathrm{Si}$ & 24 & $95 \%$ \\
$\mathrm{No}$ & 1 & $5 \%$ \\
Total & $\mathbf{2 5}$ & $\mathbf{1 0 0 \%}$ \\
\hline
\end{tabular}




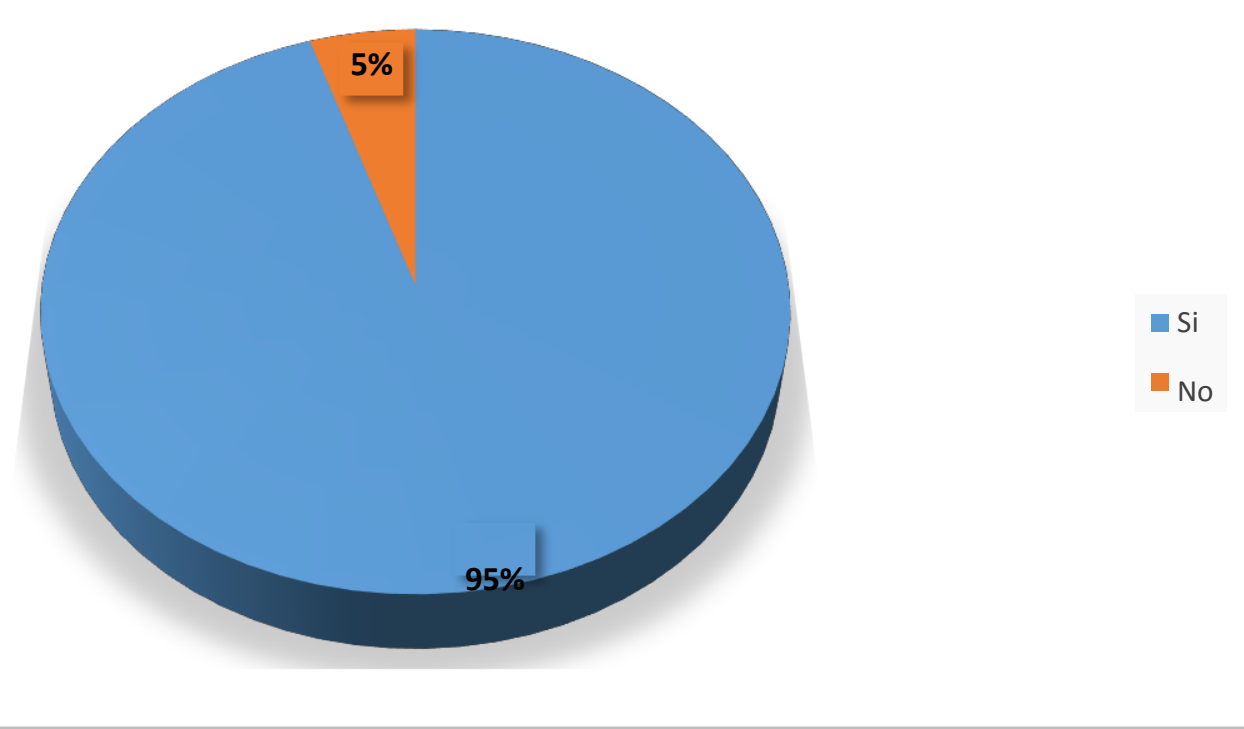

Gráfico 8. Apoyo del profesional de enfermería

Fuente: Programa Control de Tuberculosis, Centro de Salud Cisne 2

Análisis: La encuesta recogió la siguiente información, que el 95\% de los pacientes que acuden al Centro de Salud Cisne 2, si recibieron apoyo del profesional de enfermería durante el tratamiento, mientras que una minoría del 5\% de los sujetos de la investigación manifestaron que no recibieron ningún apoyo del profesional de enfermería.

Al expresar en sí que son las teorías indicamos que son estudio evaluativo del entorno comprende todo del individuo bajo los paradigmas o modelos conceptuales relacionados entre sí y sobre los cuales se bosquejan y se intentan representar o explican la enfermería, mide, cuestiona, y simboliza la acción participación del individuo, su entorno, salud. (Quintero, 2016)

Los datos refieren que el $95 \%$ de los pacientes tuvieron apoyo durante su tratamiento dando lugar que el personal de enfermería si mantiene su rol como educadora, impartiendo la motivación a cada paciente en el centro de salud, y con las visitas domiciliarias. 


\section{9. ¿Cuenta con un ingreso económico accesible para asistir a la institución?}

Tabla 19. Ingreso económico para asistir a institución

\begin{tabular}{lll}
\hline Alternativas & Frecuencia & Porcentaje \\
\hline $\mathrm{Si}$ & 15 & $60 \%$ \\
$\mathrm{No}$ & 10 & $40 \%$ \\
Total & $\mathbf{2 5}$ & $\mathbf{1 0 0 \%}$ \\
\hline
\end{tabular}

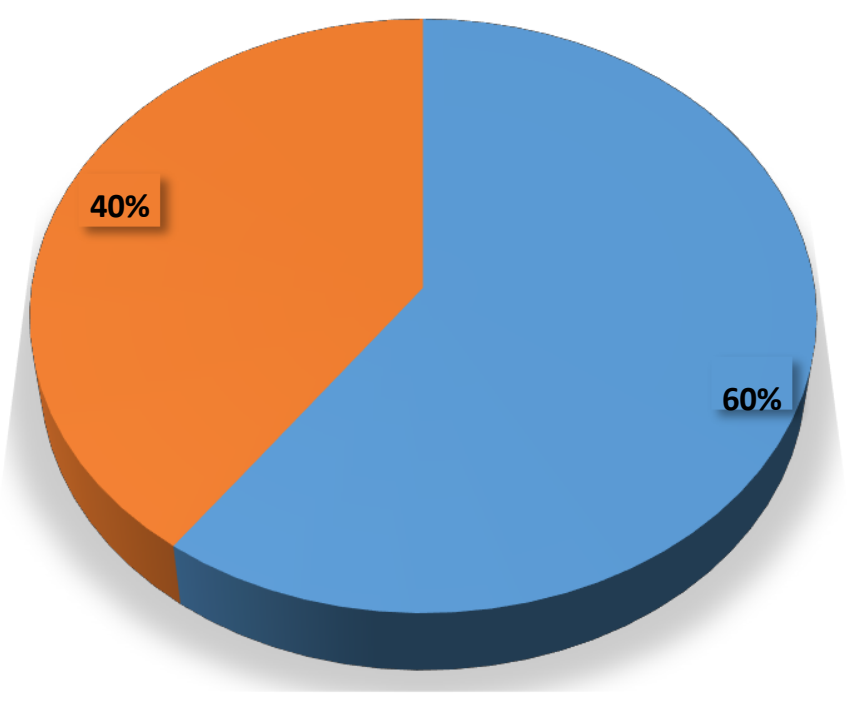

Gráfico 9. Ingreso económico para asistir a institución

Fuente: Programa Control de Tuberculosis, Centro de Salud Cisne 2

Análisis: La encuesta recogió que el 60\% de la población si mantiene un ingreso económico para asistir a la institución, mientras que el $40 \%$ manifestaron que no mantenían ingresos para la asistencia al establecimiento de salud.

Un estudio mostró que el $84.2 \%$ de los que abandonaron no tenían capacidad económica mientras que el 59.6\% de los controles presentaron esta misma situación, el riesgo de abandono fue relativamente algo y personas que no laboraban. (Beberían, 2015)

Se relaciona tanto con diversos aspectos económicos, pero también sociales ya que la existencia o no de los mismos puede determinar el tipo de calidad de vida de una familia o de un individuo, por esta razón se evidencia con la investigación realizada que el 60\% de la población con esta 
enfermedad si obtuvo apoyo económico para el traslado a la institución y lograr culminar su tratamiento sin problema alguno.

\section{Tipo de transporte que utiliza para llegar al establecimiento de salud}

Tabla 10. Tipo de transporte

\begin{tabular}{llll}
\hline Alternativas & & Frecuencia & Porcentaje \\
\hline Tricimoto & 3 & $60 \%$ \\
A pie & 1 & $15 \%$ \\
Bus & 1 & $25 \%$ \\
Total & $\mathbf{5}$ & $\mathbf{1 0 0 \%}$ \\
\hline
\end{tabular}

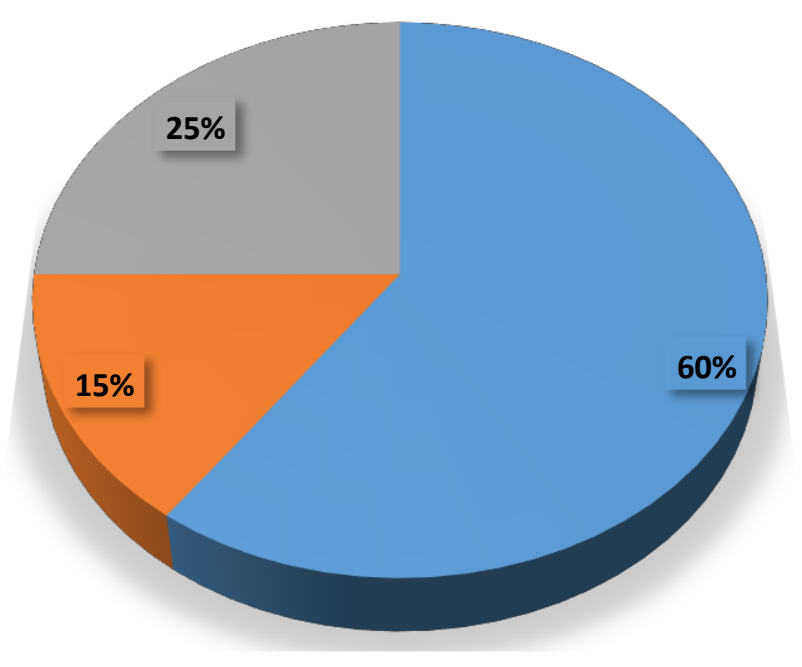

- Tricimoto

A pie

Bus

Gráfico 10. Tipo de transporte

Fuente: Programa Control de Tuberculosis, Centro de Salud Cisne 2

Análisis: La encuesta recogió la siguiente información que el 60\% de la población del estudio se traslada en tricimoto al centro de salud, mientras que el $15 \%$ refirió que prefiere ir a pie, un $25 \%$ que utiliza bus de transporte que utiliza para llegar al establecimiento de salud.

Un estudio mostró respecto al estrato económico que el $68 \%$ de los casos comprendía a la transportación hacia la institución, el 70,2\% de los controles pertenecían al estrato social bajo, observaron que el índice de abandono del tratamiento el 1,2 vivían en un estrato bajo. (Orozco, 2014) 
Tenemos en cuenta que el nivel económico afecta a los pacientes que están en el tratamiento ya que el ingreso que tienen lo ocupan para su traslado a la institución, es evidenciado en los datos estadísticos que la mayoría de pacientes con un $60 \%$ se trasladan en tricimoto diariamente para tomar la medicación, y con un índice bajo del 15\% prefiere ir a pie ya que su ingreso económico no es factible para su transportación y traslado a la institución.

\section{Temor acerca del tratamiento sobre la enfermedad}

Tabla 11. Temor sobre la enfermedad

\begin{tabular}{lll}
\hline Alternativas & Frecuencia & Porcentaje \\
\hline $\mathrm{Si}$ & 2 & $10 \%$ \\
$\mathrm{No}$ & 23 & $90 \%$ \\
Total & $\mathbf{2 5}$ & $\mathbf{1 0 0 \%}$ \\
\hline
\end{tabular}

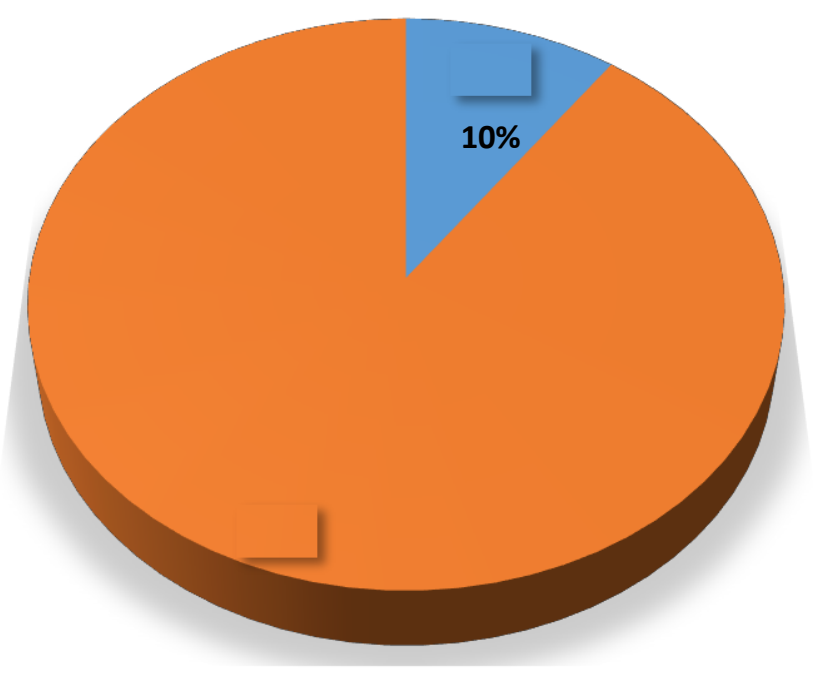

Gráfico 11. Temor sobre la enfermedad

Fuente: Programa Control de Tuberculosis, Centro de Salud Cisne 2

Elaborado por: Yaritza De La Cruz, Evelyn Lamilla

Análisis: La encuesta indica el $90 \%$ de la población de estudio refirió que no mantiene ningún tipo de temor acerca del tratamiento sobre la enfermedad, mientras que en un 10\% si manifestó sentir temor acerca del tratamiento sobre la enfermedad.

En un estudio realizado se logró constatar que el entorno de la convivencia del paciente es un ente principal, siendo así el medio de desenvolvimiento y enfocada a la culminación de un fin la 
protección del mismo, el cual se textualiza que "el sujeto vive, bajo su entorno de conveniencia y acepta dichas condicionantes, en el caso de la indagación efectivamente es así la impericia de los cambios, el medio de donde se rodeó son influyentes y concluyentes para que un individuo mantenga la responsabilidad del término de un tratamiento que solo lo beneficiara a todos los que lo rodean”. (Álvarez, 2014)

En conclusión, el temor a la enfermedad y a la sociedad puede influir en la continuación del tratamiento de la TB, en este estudio fue evidenciado con una escala de porcentaje que el $90 \%$ sintió temor alguno al recibir el tratamiento.

\section{Incomodidad en la asistencia al centro de salud mediante el tratamientoantifimico}

Tabla 12. Incomodidad en la asistencia al centro de salud

\begin{tabular}{lll}
\hline Alternativas & Frecuencia & Porcentaje \\
\hline $\mathrm{Si}$ & 2 & $10 \%$ \\
$\mathrm{No}$ & 23 & $90 \%$ \\
Total & $\mathbf{2 5}$ & $\mathbf{1 0 0 \%}$ \\
\hline
\end{tabular}

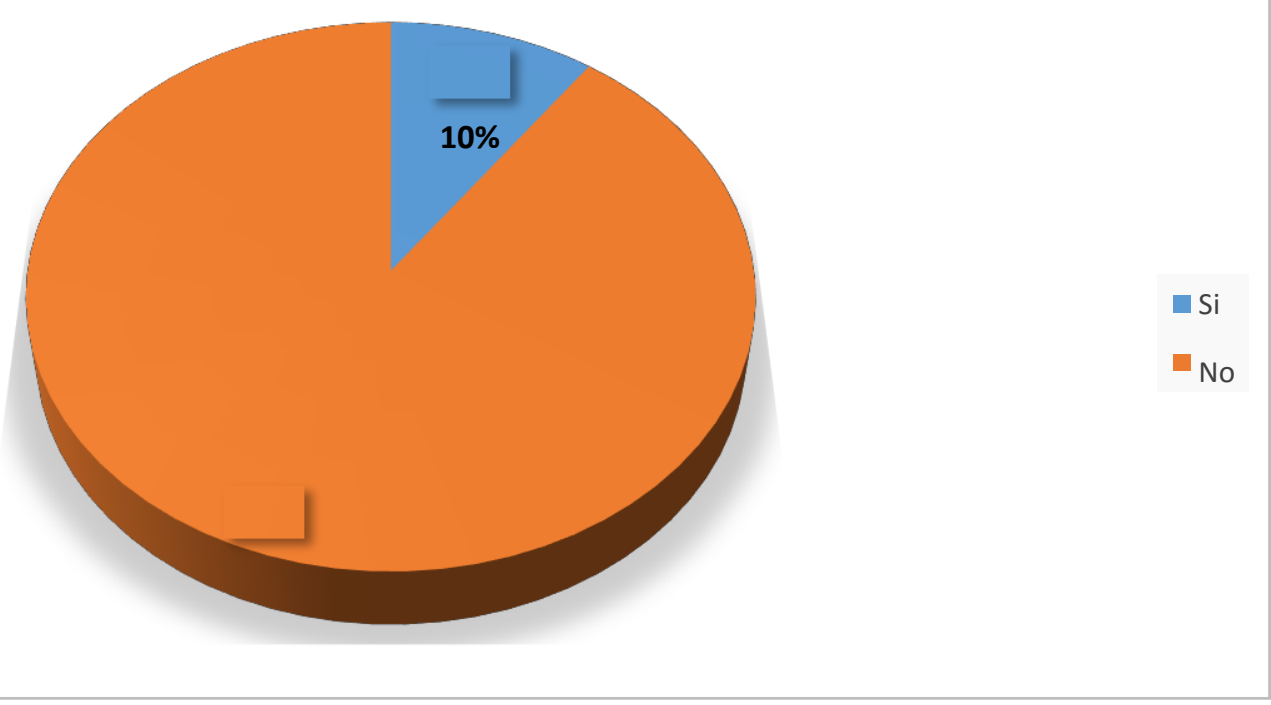

Gráfico 12. Incomodidad en la asistencia al centro de salud

Fuente: Programa Control de Tuberculosis, Centro de Salud Cisne 2

Análisis: La encuesta sostiene que el $90 \%$ de la población del estudio refirió que no mantienen una incomodidad en la asistencia al centro de salud mediante el tratamiento anti fímico, mientras 
que el $10 \%$ refirió que si tiene incomodidad en la asistencia al centro de salud mediante el tratamiento antifimico.

Se realizó un estudio descriptivo con 67 pacientes con TB que se encontraban cursando su primera etapa del tratamiento, la importancia de evidenciar y describir los principales factores que los inducían a una discontinuidad del tratamiento, el cual la incomodidad al acudir a la institución era un 56\% de relevancia para estos pacientes. (Arce, 2014)

En conclusión, en este estudio de investigación podemos observar que el $90 \%$ no obtuvo ningún tipo de incomodidad en la asistencia a la toma de medicación en la institución, mientras que el $10 \%$ que obtuvo la incomodidad es el que está en número de abandonos del tratamiento.

\section{Conocimiento acerca de la enfermedad de la tuberculosis}

Tabla No. 13 Conocimiento sobre la tuberculosis

\begin{tabular}{lll}
\hline Alternativas & Frecuencia & Porcentaje \\
\hline Mucho & 12 & $50 \%$ \\
Poco & 8 & $30 \%$ \\
Nada & 5 & $20 \%$ \\
Total & $\mathbf{2 5}$ & $\mathbf{1 0 0 \%}$ \\
\hline
\end{tabular}

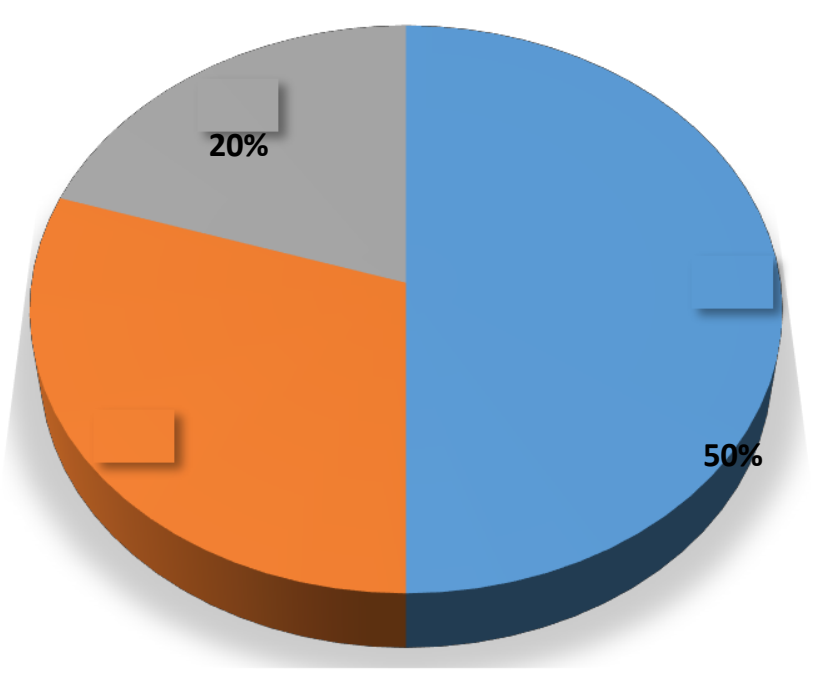

Gráfico 13. Conocimiento sobre la tuberculosis Fuente: Programa Control de Tuberculosis, Centro de Salud Cisne 2 Elaborado por: Yaritza De La Cruz, Evelyn Lamilla 
Análisis: La encuesta muestra que el $50 \%$ de la población refirió que si mantiene información acerca de la enfermedad de la tuberculosis, mientras que un 30\% manifestó que poco, y por ultimo 20\% refirió que prefiere mantenerse informado más acerca de la patología.

En conclusión, en el estudio se evidenció que la institución si otorgó la información necesaria para los pacientes del programa, pero no obstante hubo un déficit de abandono en el periodo 2017 por parte de ciertos pacientes que no obtuvieron la información correcta, evidenciándolo con un $30 \%$ acerca del abandono en el tratamiento.

\section{4. ¿Qué tipo de molestias ha sentido en el transcurso del tratamiento?}

Tabla 14. Molestias durante el tratamiento

\begin{tabular}{lcr}
\hline Alternativas & Frecuencia & Porcentaje \\
\hline $\begin{array}{l}\text { Nauseas, vómitos, ardor en el } \\
\text { estómago, diarreas }\end{array}$ & 5 & $20 \%$ \\
$\begin{array}{l}\text { Sarpullidos en el cuerpo, picazón en } \\
\text { piel, heridas de piel }\end{array}$ & 3 & $10 \%$ \\
$\begin{array}{l}\text { Dolores musculares, dolor de huesos, } \\
\text { desorientación }\end{array}$ & 12 & $50 \%$ \\
$\begin{array}{l}\text { Otros } \\
\text { Total }\end{array}$ & 5 & $20 \%$ \\
\hline
\end{tabular}

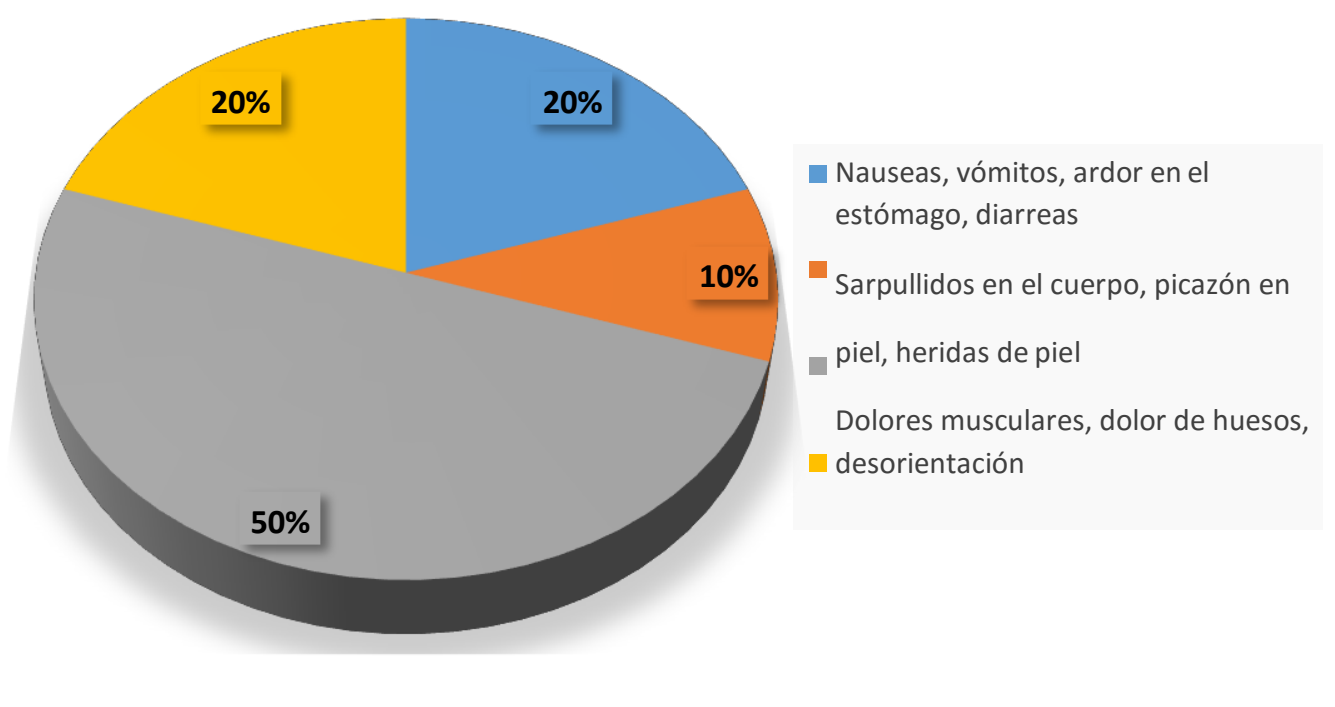

Gráfico 14. Molestia durante el tratamiento 
Fuente: Programa Control de Tuberculosis, Centro de Salud Cisne 2

Análisis: La encuesta recogió la información con los sujetos de investigación manifestaron que el $50 \%$ de los tipo de molestias ha sentido en el transcurso del tratamiento, presentaron dolores musculares, dolor de huesos, desorientación, mientras que un 20\% manifestaron nauseas, vómitos, ardor en el estómago, diarreas, seguido por un $20 \%$ con otro tipo de molestias, seguido por otro grupo de investigación que fue $20 \%$, y culminando con un $10 \%$ de sarpullido en el cuerpo de esos, piel heridas de la piel.

\section{5. ¿Cuántas visitas domiciliarias se realizó durante el tratamiento de tuberculosis?}

Tabla 15. Visitas domiciliarias

\begin{tabular}{lcc}
\hline Alternativas & Frecuencia & Porcentaje \\
\hline 1 vez & 3 & $15 \%$ \\
2 veces & 18 & $65 \%$ \\
Varias veces & 4 & $20 \%$ \\
Total & $\mathbf{2 5}$ & $\mathbf{1 0 0 \%}$ \\
\hline
\end{tabular}

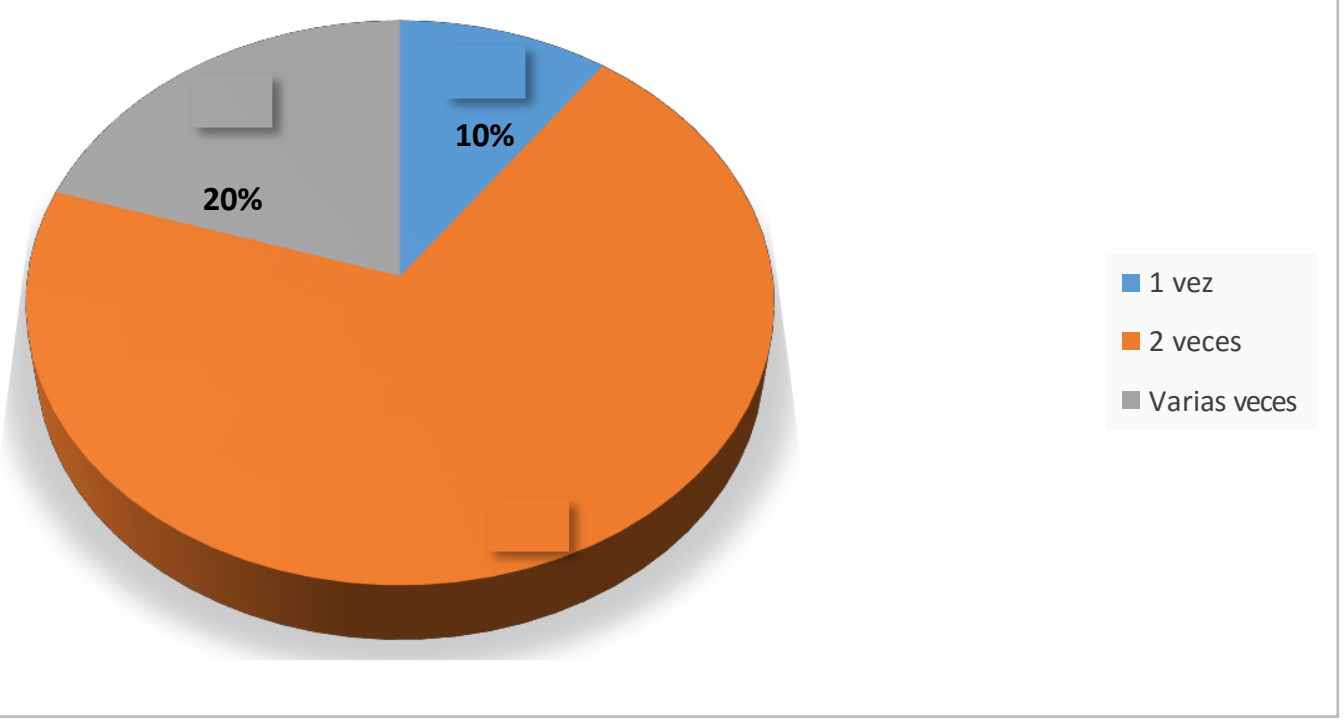

Gráfico 15. Visitas domiciliarias

Fuente: Programa Control de Tuberculosis, Centro de Salud Cisne 2

Análisis: Los datos refieren información acerca de las visitas domiciliarias que se realizó durante el tratamiento de tuberculosis, en donde el $70 \%$ manifestó que dos veces al mes, seguido por 10\% que solo asistió el personal de enfermería una vez a la visita domiciliaria, por otro lado el $20 \%$ 
manifestó varias veces.

En conclusión, la visita domiciliaria realizada a los pacientes que se encuentran en la falta de la toma de medicación debe ser más consecuente para que estos no abandonen el tratamiento, ya que en este estudio se evidenció que fue el $15 \%$ de los abandonos que no recibieron la visita domiciliaria adecuada consecuencia de esto es el abandono al tratamiento.

\section{Consideraciones finales de los resultados de analisis de datos}

Para una adecuada adherencia al tratamiento antituberculoso, es importante que interactúen una diversidad de factores, en nuestra investigación, los factores han sido agrupados a través del esquema de la encuesta, dicha agrupación nos ha permitido identificar entre los factores de riesgo relacionados a la biología humana el presentar sexo masculino, como un riesgo para el abandono del tratamiento antituberculoso, al respecto la bibliografía existente es coincidente, con nuestro estudio, es decir los hombres estudiados pueden presentar 1,2 veces el riesgo de abandonar el tratamiento; sin embargo al contrastar estas variables en el análisis multivariado no se verificó la relación entre las variables.

De la encuesta realizada se obtuvieron los siguientes datos que el 95\% de la población del estudio pertenecen al género masculino, mientras que el $5 \%$ son de género femenino, siendo este relevante que la más alta de los sujetos de la indagación son hombres, objetando que el porcentaje inferior pertenece a las damas, mientras que los pacientes con tuberculosis que asisten a la toma de medicación en el Centro de Salud Cisne 2 en un promedio de edad de 20 a 39 años se mantiene con un porcentaje del $80 \%$ de la población seguido por un $15 \%$ que oscilan entre edades de 40 a 59 años, y culminando con 5\% de 60 años y más. 90\% de la población pertenece al sector urbano mientras que un $10 \%$ al sector rural, siendo esto una población numerosa, altamente densa, y dedicada principalmente a actividades del sector secundario, Asimismo, los espacios urbanos cuentan con complejas infraestructuras para el suministro de servicios, como agua, electricidad, transporte y comunicaciones.

Un indicativo importante en la investigación siendo que el 70\% de los sujetos de la población objetaron que no mantienen ningún tipo de consumo de drogas, mientras que otro $30 \%$ arrojo que 
si son consumidores de estupefacientes.

Una observación principal en el estudio que se realizo es el 90\% de la población si mantuvo apoyo familiar cuando presento la enfermedad, mientras que un porcentaje del $10 \%$ contesto que no mantuvieron ningún tipo de apoyo por parte de sus familiares cercanos ni lejanos. Por otro lado debemos manifestar que esperamos que este trabajo se constituya en un aporte para la amplia bibliografía existente en el país y en Latinoamérica acerca de abandono de tratamiento en el programa de tuberculosis, conocemos de las limitaciones de nuestro estudio propias de los estudios de casos y controles como el sesgo de memoria entre otras limitaciones, así como la dificultad económica de plantear un estudio que comprenda todas los departamentos del país, sin embargo consideramos que es la mayor aproximación en cuanto a abandono de tratamiento que se haya realizado para bien de la comunidad antes estudiada, y evaluada. Por otro lado, el conocer previamente al tipo de participante puede evidenciar un sesgo de selección, quizás el mejorar el tamaño de nuestra población de estudio pudo mejorar la potencia del análisis multifactorial para evaluar asociaciones e interacciones de interés, al ingresar simultáneamente varias covariables en el modelo. Por otra parte, siempre los factores relacionados a los estilos de vida especialmente los hábitos nocivos, resultan difíciles de explorar a través de metodología que se aplicó en el estudio debido a que mucha de esta información en muchos casos no quiere ser compartida por los entrevistados, por lo que a veces para una mejor exploración se requiere de metodología cualitativa, lo que podría explorarse con estudios de mayor profundidad.

\section{Conclusiones}

En este presente proyecto de investigación se logró determinar los factores que inducen al abandono del tratamiento ingresadas en el programa de prevención y control de Tuberculosis del Centro de Salud Cisne II perteneciente al Distrito 09D04, con una población de 25 pacientes en el año 2017 el cual se presenta una cifra de 15 usuarios que abandonaron el tratamiento con la incidencia de que el sexo masculino es el más prevalente en la descontinuación de este. Loa factores sociales: Tenemos a los adultos jóvenes comprendido entre los 20 y 40 años de edad, de sexo masculino $(95 \%)$.

De acuerdo con los objetivos se logró obtener los resultados en los factores personales: El cual se 
determinó que las reacciones adversas como fiebre, dolores musculares, cefaleas, ardor al estómago, náuseas y vómitos por la gran cantidad de medicamentos antifimicos que conlleva el tratamiento, esto lleva al paciente a no continuar con ello, dando en un $50 \%$.

En los factores sociales y económicos se logró evidenciar que el 60\% de la población si mantiene un ingreso económico para asistir a la institución, mientras el $40 \%$ tienen un bajo recurso económico para la trasladación a la unidad de salud, índice del cual fue expuesto para el abandono del tratamiento. En cuanto a los factores sociales se logró evidenciar que el $20 \%$ de los pacientes que no mantuvieron apoyo sea familiar y social son los que no continuaron con el tratamiento.

De acuerdo al objetivo sobre el factor educativo, los resultados obtenidos nos ayudaron evidencia que el $20 \%$ de estos pacientes no obtuvieron la información necesaria el cual afecto para la continuación de su tratamiento.

\section{Referencias Bibliográficas}

Álvarez, M. (2014). Teoría Básica de las Necesidades A. Maslow. Barcelona: Español.

Ramirez AMC, Ramirez JMC. (2015). Factores asociados al éxito del tratamiento de los pacientes con tuberculosis. Medellin: Colombiano.

Arce, H. W. (2014). Manejo de pacientes tuberculosis. En H. W. Arce, Manejo de pacientes con tuberculosis (pág. 102). Cuba: Lahabana.

Cristhian, V. (31 de 08 de 2016). Medlineplus. Obtenido de Medlineolus: www.medlineplus.gov

D, Bernal Ruiz, S. Horta Buitrago. (2014). Cuidados de enfermería en pacientes critico desde la teoría de comprensión facilitada. Mexico: Universidad Nacional Autónoma de México.

G Beberían. (2015). Estudio descriptivo factores económicos de pacientes con tuberculosis. Chile, Santiago, Chile: Revista chilena- SciELO.

Holger, F. (2014). “INCIDENCIA, DIAGNÓSTICO, TRATAMIENTO, 
EVOLUCIÓN, Y. Loja: Universidad Nacional de Loja.

Keith L. Moore, T. V. N. Persaud, Mark G. Torchia. (2009). Embiologia Clínica.

En T. V. Keith L. Moore, Embiologia Clínica (pág. 526). España: Elsevier.

Leon, P. R. (2014). Tuberculosis pulmonar, diagnostico, programa control. Revista Habana Ciencia Medicas, 23.

Miranda, C. (2012). Estudio de casos de abandono del tratamiento de tuberculosis. Tapachula, Chiapas. México.

MSP. (2014). Tuberculosis tratamiento en el Ecuador. Quito: El Telégrafo.

MSP. (2015). La tuberculosis en el Ecuador. MSP, La tuberculosis en el Ecuador, 24.

OMS. (2013). Tuberculosis si se cura. Usa: OMS, ediciones.

OMS. (2015). Porcentajes mundiales de países con mayor índice de tuberculosis, tratamiento, ausentismo de la medicación. Usa: OMS.USA.

Orozco, C. y. (2016). Abandono del tratamiento de tuberculosis. Brasil: Brasileño.

Quintero, Q. (2017). Estudio de las Teorias del cuidado humano. Chile: Santagueño.

Rodríguez D, Juan Carlos, Undurraga, Álvaro F. (2014). Enfermedades Respiratorias, intervenciones de enfermeria. España: Mediterráneo Publicaciones Técnicas.

Sampieri, S. (2014). Metodologia de la Investigacion. Mexico: Mexicana.

Yach, D. (2013). El incumplimiento del tratamiento prescrito para las enfermedades crónicas es un problema mundial de gran envergadura. En OMS, El incumplimiento del tratamiento prescrito para las enfermedades crónicas es un problema mundial de gran envergadur (pág. 99). Madrid: Español. 
Zaforteza C., De Pedro E., Gastaldo D., Lastra P., Sánchez P. (2014). Cuidados intensivos de su relación con los familiares del paciente crítico?. Enferm Intensiva. En D. P. Zaforteza C., Cuidados intensivos de su relación con los familiares del paciente crítico?. Enferm Intensiva. (pág. 156). Argentina: Argentino. 